\title{
Obtenção de hydrochar a partir de carbonização hidrotérmica de cascas do fruto de Magonia pubescens A. St. Hil. Sapindaceae: Caracterização e avaliação em processo de adsorção
}

\author{
Obtaining hydrochar via hydrothermal carbonization of \\ Magonia pubescens A. St. Hil. Sapindaceae fruit bark: \\ Characterization and evaluation of its adsorptive \\ properties
}

\author{
Romario Victor Pacheco Antero ${ }^{1}$, Meire Ellen Gorete Ribeiro Domingos ${ }^{2}$, \\ Lorrayne Lins Suzuki ${ }^{2}$, Sergio Botelho de Oliveira ${ }^{3}$; \\ Satu Anneli Ojala ${ }^{4}$, Andressa Regina Vasques Mendonça ${ }^{1}$,
} Sarah Silva Brum ${ }^{1}$

\footnotetext{
${ }^{1}$ Instituto de Química, Universidade de Brasília. Campus Universitário Darcy Ribeiro, 70910-900, Brasília, DF, Brasil.

${ }^{2}$ Departamento de Engenharia Química, Universidade de São Paulo- Escola Politécnica da USP, 05508-010, São Paulo, São Paulo, Brasil

${ }^{3}$ Departamento de Química, Instituto Federal de Goiás- Campus Goiânia, CEP: 74055-110, Goiânia, Goiás, Brasil

${ }^{4}$ University of Oulu, Faculty of Technology, Environmental and Chemical Engineering, FI-90014. P.O. Box 4300, Oulu, Oulu, Finland.

e-mail: drvictor.pacheco@outlook.com'sarahbrum@unb.br, andressavasques@unb.br, meireellengorete@gmail.com, lorraynelinssuzuki@gmail.com,dr_botelho@yahoo.com.br, satu.ojala@oulu.fi
}

\section{RESUMO}

A Carbonização hidrotermal (HTC) de cascas do fruto de Magonia pubescens A. St. Hil. Sapindaceae (Tingui do cerrado) é apresentada como uma proposta inédita na produção de hydrochars a partir de precursores de espécies do Cerrado Brasileiro, onde se verificou a influência da temperatura nas propriedades dos materiais obtidos. Os hyrochar obtidos foram caracterizados em termos de rendimento em peso, análise elementar e estimativa do poder calorífico superior (PCS), análise de espectroscopia na região do infravermelho (FT-IR), difratometria de raios-X (DRX) e avaliação da capacidade de adsorção. O aumento da temperatura afetou negativamente o rendimento do hydrochar, o qual variou entre $46,25 \%$ e $27,42 \%$, nas temperaturas de 170 e $190{ }^{\circ} \mathrm{C}$, respectivamente. Hydrochars com maior teor de carbono $(64,10 \%)$ foram obtidos em baixa temperatura $\left(170{ }^{\circ} \mathrm{C}\right)$, o qual também apresentou maior poder calorífico superior $\left(23,94 \mathrm{MJ} \mathrm{kg}^{-1}\right)$ e área superficial específica $\left(44,0 \mathrm{~m}^{2} \cdot \mathrm{g}^{-1}\right)$. A evolução das razões atômicas H/C e O/C indicou processos de desidratação e descarboxilação durante a carbonização hidrotérmica. As isotermas de adsorção-dessorção de $\mathrm{N}_{2}$ a $-176{ }^{\circ} \mathrm{C}$, resultantes da análise das propriedades texturais e estruturais, demonstraram a presença de mesoporos na estrutura dos hydrochars. Na avaliação da capacidade de adsorção com azul de metileno, a isoterma de Langmuir foi a que melhor explicou o comportamento de adsorção, tendo os hydrochars obtidos a 170 e $180{ }^{\circ} \mathrm{C}$ as maiores capacidades de adsorção (139,38 e 202,40 $\mathrm{mg} \mathrm{g}^{-1}$, respectivamente). Os resultados indicaram a carbonização hidrotermal de cascas do fruto de tingui como uma nova estratégia para o desenvolvimento de hydrochars com alto rendimento, teor de carbono elevado e alta eficiência de adsorção, valores superiores a diversos trabalhos encontrados na literatura.

Palavras-chave: Carbonização hidrotermal. Tingui do Cerrado. Adsorventes alternativos. Azul de metileno.

\section{ABSTRACT}

The hydrothermal carbonization (HTC) of bark of the fruit of Magonia pubescens A. St. Hil. Sapindaceae (Tingui do Cerrado) presents as an unprecedented proposal for the production of hydrochars from precursors of Brazilian Cerrado species, where the influence of temperature on the properties of the obtained materials is verified. The obtained hydrochar were characterized in terms of yield, elemental analysis, estimation of the higher calorific value, infrared spectroscopy, X-ray diffractometry, and methylene blue adsorption. The tem- 
perature increases affected negatively hydrochar yield, which varied between $46,25 \%$ and $27,42 \%$, at temperatures of 170 and $190{ }^{\circ} \mathrm{C}$, respectively. Hydrochar with higher carbon content $(64,10 \%)$, higher calorific value $\left(23,94 \mathrm{MJ} \mathrm{kg}^{-1}\right)$ and specific surface area $\left(44,0 \mathrm{~m}^{2} \mathrm{~g}^{-1}\right)$ were obtained at $170{ }^{\circ} \mathrm{C}$. The evolution of the atomic ratios $\mathrm{H} / \mathrm{C}$ and $\mathrm{O} / \mathrm{C}$ indicated processes of dehydration and decarboxylation during hydrothermal carbonization. The adsorption-desorption isotherms of $\mathrm{N}_{2}$ at $-176^{\circ} \mathrm{C}$ resulting from the analysis of the textural and structural properties demonstrated the presence of mesopores in the structure of the hydrochars. In the evaluation of the adsorption capacity with methylene blue, the adsorption data correlated well with the Langmuir isotherm. In this analysis, the hydrochars obtained at 170 and $180{ }^{\circ} \mathrm{C}$ demonstrated the highest adsorption capacity $\left(\mathrm{Q}_{\max }=139,38\right.$ and $202,40 \mathrm{mg} \mathrm{g}^{-1}$, respectively). The results indicated the hydrothermal carbonization of the bark of the tingui fruit as a new strategy for the development of hydrochars with high yield, high carbon content and high adsorption efficiency, higher values than several papers found in the literature.

Keywords: Hydrothermal carbonization. Tingui do Cerrado. Alternative Adsorbents. Methylene blue.

\section{INTRODUÇÃO}

A busca por novas metodologias para obtenção de materiais de engenharia vem ocupando destaque na química de materiais, focada principalmente na utilização de precursores provenientes de resíduos para o desenvolvimento de produtos com estrutura carbonácea desenvolvida, contemplando temas ambientais, econômicos e sociais [1]. Sob essas condições, a metodologia de carbonização hidrotermal (HTC) vem se sobressaindo, mostrando-se atraente devido à sua simplicidade, baixo custo e eficiência energética [2]. Em termos gerais, a técnica consiste em reagir o precursor com água em uma autoclave utilizando temperaturas entre $150 \mathrm{e}$ $260{ }^{\circ} \mathrm{C}$, sob pressões autogeradas [3]. Ao longo do processo, o material precursor sofre uma série de reações de estruturação e decomposição, iniciando com a hidrólise, seguida por desfuncionalização, tais como desidratação e descarboxilação, e finalmente, recondensação e aromatização [4], obtendo ao final do processo um material carbonáceo denominado hydrochar [5].

HU et al. [6] relatam que o tratamento da biomassa sob condições hidrotérmicas aumenta ou modifica a solubilidade desses materiais, acelera a interação física e química entre reagentes e solventes e facilita reações iônicas ácido/base, além de conduzir a precipitação/formação de estruturas carbonáceas. Comparado com o material precursor, o hydrochar tem demonstrado propriedades para atuar como combustível sólido devido ao seu alto teor carbonáceo, baixo teor de oxigênio e poder calorífico elevado. Além disso, apresenta propriedades de adsorção de gases, como um possível agente de sequestro de gases de efeito estufa [7], precursor para síntese de carbono ativado [8,9], adsorventes alternativos [10], condicionadores de solo [11], etc. Contudo, embora a HTC seja uma técnica versátil e promissora, muitas pesquisas ainda precisam ser desenvolvidas com intuito de compreender os processos, mecanismos e reações químicas complexas envolvidas no processo, o que tende a proporcionar o emprego de materiais precursores diferenciados e tornar a metodologia mais abrangente.

A relação entre a carbonização hidrotermal e o desenvolvimento de adsorventes alternativos tem ganhado ênfase devido às constantes problemáticas atuais de escassez de água potável. Atualmente, a crescente demanda por corantes comerciais em várias indústrias tem levado à produção em massa desses componentes. Mais de $1,00 \times 10^{5}$ tipos de corantes comerciais estão disponíveis, com produção anual superior a 7,00 $\times$ $10^{5}$ toneladas, a maioria deles são descarregados diretamente no meio aquoso [12], ocasionando uma série de problemas ambientais. $\mathrm{O}$ descarte incorreto desses corantes pode causar inúmeros efeitos colaterais, como mutagenicidade, toxicidade embrionária, teratogenicidade e carcinogenicidade, bem como danos ao fígado, cérebro e sistema nervoso central e reprodutivo, resultando em disfunção renal [12-14]. Nesse aspecto, o processo adsorção tem se intensificado como método de purificação e como pré tratamento em diversos processos industriais. $\mathrm{O}$ azul de metileno (AM) é constantemente empregado como molécula modelo para a análise da capacidade de adsorção de materiais carbonáceos adsorventes, além de ser considerado como contaminante potencial de diversos efluentes. Devido às aplicações intensas na indústria química, na área biológica, ciência médica e indústrias de tintas [15] e à sua relação com as problemáticas citadas, atualmente muitos pesquisadores estão cada vez mais preocupados com a remoção de corantes orgânicos do meio aquoso, entre os quais cita-se o azul de metileno [12,16-20].

Dentre os biomas característicos do Brasil destaca-se o cerrado, uma das mais ricas savanas do mundo e considerada como um dos "hotspots" mundiais de biodiversidade, compreendendo cerca de $23 \%$ do território brasileiro [21]. Entre suas inúmeras espécies com potencial científico destaca-se a Magonia pubescens Sapindaceae, popularmente conhecida como Tingui. A árvore é ornamental devido ao aspecto redilhado da folhagem, podendo ser empregada na composição de jardins, praças e ruas estreitas, além de ser indicada 
para plantio em áreas degradadas e de preservação permanente [22]. A espécie varia de 5 a $10 \mathrm{~m}$ de altura, apresentando madeira pesada e escura usada na construção civil. O caule é rendilhado, com folhas compostas paripinadas e flores amarelo-esverdeadas. Seus frutos são caracterizados como cápsula trivalvar de coloração marrom-escura, contendo muitas sementes oleaginosas. A dispersão é predominantemente anemocórica, com floração e maturação dos frutos durante os meses de agosto e setembro [23].

Estudos acerca do tingui começaram a despontar apenas recentemente, embora a planta tenha sido indicada com potencialidades científicas por vários naturalistas europeus no século XIX. O cirurgião escocês botânico George Gardner (1812-1849) foi um deles, apresentando a espécie Magonia pubescens em seu livro "Catalogue of Brazilian Plants- Travels in the Interior of Brazil" sobre o uso de plantas nativas pelo povo brasileiro e avaliar a extensão em que foram exploradas, juntamente com outras 63 espécies [24]. As sementes oleaginosas são muito empregadas na fabricação de sabão [23]. Na medicina popular, o caule macerado é usada em tratamentos ulcerosos, enquanto infusões das raízes são empregadas para envenenar os peixes [24] em práticas nativas de pesca. As sementes de tingui tambem causam abortos em bovinos, o que tem ocasionado sua retirada das pastagens naturais do cerrado, sendo por isso forte candidata à extinção [25]. A velocidade com que esse processo vem ocorrendo é razão suficiente para o desenvolvimento de estudos sobre a importância de propagação da espécie, visando tanto a produção de materiais com valor de mercado e para fins científicos, quanto para a sua conservação.

Fundamentando-se nos pressupostos discutidos, o trabalho enfatiza a carbonização hidrotermal das cascas do fruto da Magonia pubescens (MP) para obtenção de materiais carbonáceos (hydrochar), considerando os efeitos das condições de processo HTC (temperatura, tempo de reação e proporção água:biomassa), tendo a temperatura como variável, de maneira a compreender seus efeitos nas propriedades e no rendimento do hydrochar. Os materiais obtidos foram caracterizados e avaliados como adsorvente alternativo na remoção do corante azul de metileno. A espécie em análise foi escolhida por ser facilmente localizada, ainda não estudada em processos de carbonização hidrotermal e por apresentar estrutura lignocelulósica, componentes responsáveis pela estrutura e multifuncionalidade do hydrochar [26]. Além disso, embora a carbonização hidrotermal seja um tema amplamente estudados mundialmente, publicações em periódicos nacionais ainda são escassas [9,27], e tendo em vista que o Brasil é um dos maiores produtores mundiais de resíduos de biomassa, muito ainda pode ser pesquisado e diversos produtos podem ser obtidos mediante consolidação da técnica. A partir da atual pesquisa também pretende-se chamar atenção para o uso sustentável do cerrado, suas potenciais fontes de pesquisa e desenvolvimento econômico e social.

\section{MATERIAIS E MÉTODOS}

\subsection{Coleta e preparo das amostras}

Os frutos de tingui Magonia pubescens (MP) empregados nos experimentos foram coletados na região de cerrado brasileiro, localizada na cidade Buriti de Goiás, Estado de Goiás, conforme informações territoriais disponíveis na Figura 1. A quantidade de matéria-prima coletada foi entre 2,0 e 4,0 kg. A areia visível, o solo e outros contaminantes foram removidos com auxílio de um pincel com cerdas ásperas durante a coleta. Após coleta, os materiais foram lavados em água destilada e seguidamente secos em estufa a $60{ }^{\circ} \mathrm{C}$ por $3 \mathrm{~h}$. As amostras secas foram fragmentadas em moinho de facas $\left(\mathrm{SOLAB}^{\circledR}\right.$ SL 31) e separadas por granulometria em peneiras ASTM (Mesh) com diferentes malhas, empregando-se nos testes partículas que passaram pela malha 60 mesh $(250 \mu \mathrm{m})$. 


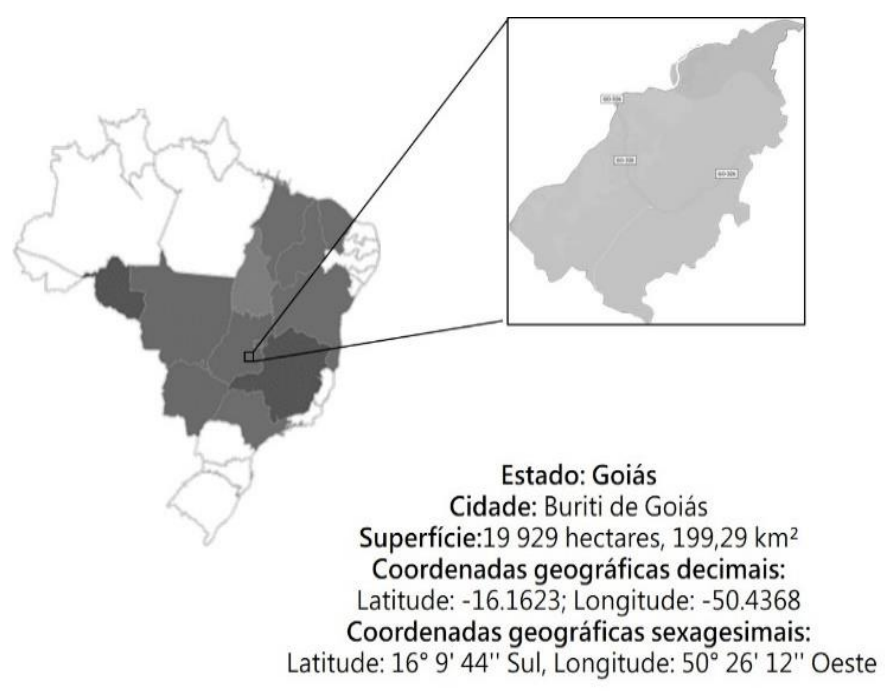

Figura 1: Informações territoriais e coordenadas geográficas referentes ao local de coleta das amostras em estudo.

\subsection{Processo de carbonização hidrotermal}

A carbonização hidrotérmica das cascas do fruto de tingui (MP) foi realizada em uma autoclave de aço inoxidável. Em cada ensaio, aproximadamente 3,0 g de biomassa foram dispersas em $30 \mathrm{~mL}$ de água destilada, mantendo a relação 1:10 (m:v) e transferida para a autoclave. O sistema foi então mantido à temperatura de 170,180 e $190{ }^{\circ} \mathrm{C}$ durante $5 \mathrm{~h}$ e os produtos hidrotermicamente obtidos (hydrochar) foram arrefecidos até a temperatura ambiente, filtrados em um sistema a vácuo, lavados com água destilada e secos a $105^{\circ} \mathrm{C}$ durante $6 \mathrm{~h}$. Ao final do processo obtiveram-se as amostras "hydrochar tingui" (HT) diferenciadas pela temperatura de tratamento hidrotermal: HT1 $\left(170{ }^{\circ} \mathrm{C}\right)$, HT2 $\left(180{ }^{\circ} \mathrm{C}\right)$ e HT3 $\left(190{ }^{\circ} \mathrm{C}\right)$, as quais foram armazenadas em recipientes herméticos e posteriormente caracterizadas. As condições reacionais mencionadas foram escolhidas após levantamento bibliográfico a respeito das principais variáveis de resposta discutidas na literatura [28-30].

\subsection{Metodologias de caracterização}

\subsubsection{Análise de rendimento do hydrochar (\% peso)}

Os hydrochars foram caracterizados em termos do seu rendimento em peso de sólido (peso \%) através da Equação 1, conforme sugerem algumas metodologias [16, 17].

$\mathrm{R}_{\mathrm{H}}(\%)=\left(\frac{\mathrm{M}_{\mathrm{H}}}{\mathrm{M}_{\mathrm{B}}}\right) \cdot 100$

Onde: $\mathrm{R}_{\mathrm{H}}(\%)=$ rendimento do hydrochar $\mathrm{M}_{\mathrm{H}}=$ massa do hydrochar seco. $\mathrm{M}_{\mathrm{B}}=$ massa da biomassa seca.

\subsubsection{Análise elementar e estimativa do poder calorífico superior (PCS)}

As composições elementares ( $\mathrm{C}, \mathrm{H}, \mathrm{N}$ e $\mathrm{O}$ ) foram determinadas utilizando um analisador elementar CHNSEA 2400 Series II (Perkin Elmer ${ }^{\circledR}$ ). O teor de oxigênio foi obtido por diferença. O poder calorífico superior (PCS) (MJ kg ${ }^{-1}$ ) dos materiais foi investigado a partir da Equação 2, considerando os valores de C, $\mathrm{H}, \mathrm{O}$ e $\mathrm{N}$ determinados durante a análise elementar, conforme estabelecido na literatura [33].

$$
\mathrm{P}_{\mathrm{CS}}=\{33,5 . \% \mathrm{C}+142,3 . \% \mathrm{H}-15,4 . \% \mathrm{O}-14,5 . \% \mathrm{~N}\} \cdot 10^{-2}
$$

Onde: $\mathrm{P}_{\mathrm{CS}}=$ poder calorífico superior; $\mathrm{C}, \mathrm{H}, \mathrm{O}, \mathrm{N}=$ teores de carbono, hidrogênio, oxigênio e nitrogênio em percentagem, respectivamente. 


\subsubsection{Análise de espectroscopia na região do infravermelho (FT-IR)}

Os grupos funcionais foram investigados por espectroscopia na região do infravermelho com Transformada de Fourier (FT-IR) empregando-se um espectrofotômetro modelo FT-IR IR-Prestige-21 (Shimadzu ${ }^{\circledR}$ ). A amostra de biomassa seca $(5,00 \pm 0,05 \mathrm{mg})$ foi misturada com $\operatorname{KBr}(150,00 \pm 0,05 \mathrm{mg})$ e comprimida para formar pastilhas. Os espectros foram obtidos na região do infravermelho médio com número de onda entre 400 a $4000 \mathrm{~cm}^{-1}$, resolução de $4 \mathrm{~cm}^{-1}$ e número de varredura (scans) igual a 60 acumulações.

\subsubsection{Difratometria de Raios-X (XRD)}

Para as análises de DRX, as amostras foram dispostas sobre um suporte de fundo livre e introduzidas no dispositivo DRX. Posteriormente os difratogramas foram obtidos utilizando-se um difratômetro modelo D8 Focus $\left(\right.$ Brucker $\left.^{\circledR}\right)$, sendo a velocidade de varredura $1,0^{\circ} \mathrm{min}^{-1}$, com passo de $0,05^{\circ}$ e variação angular de 0 a $30^{\circ}$ (20).

\subsubsection{Análise das propriedades texturais do hydrochar}

As propriedades texturais foram estimadas através da adsorção física de $\mathrm{N}_{2}(77 \mathrm{~K})$, em um aparelho Quantachrome, modelo NOVA-2200E. A área superficial específica foi determinada pelo método BrunauerEmmett-Teller (BET) usando as isotermas de adsorção. O volume total de poros foi calculado a partir da quantidade de nitrogênio adsorvida em P/P0, aplicando o método Barrett-Joiner-Halenda (BJH) [34].

\subsubsection{Avaliação da capacidade de adsorção}

Inicialmente preparou-se uma solução estoque de $1000 \mathrm{mg} \mathrm{L}^{-1}$ do corante azul de metileno (Sigma-Aldrich) em água destilada, a partir da qual desenvolveu-se as demais soluções para construção das isotermas. Para os testes de adsorção, 10,0 mg do adsorvente foram colocadas em contato com $10 \mathrm{~mL}$ de soluções de azul de metileno em várias concentrações $\left(10,25,50,100,250\right.$ e $\left.500 \mathrm{e} 1000 \mathrm{mg} \mathrm{L}^{-1}\right)$ por $24 \mathrm{~h}$ à temperatura ambiente e pH 5,3 (normal da solução). A concentração restante do AM foi analisada em um espectrofotômetro UV/VIS (Shimadzu ${ }^{\circledR}$ UV-2450) no comprimento de onda de $645 \mathrm{~nm}$.

As isotermas de adsorção para cada adsorvente avaliado foram descritas quantitativamente por parâmetros obtidos a partir do ajuste dos dados experimentais às equações não linearizadas, dos modelos de Langmuir e Freundlich. Para isso, os dados obtidos foram tratados e as isotermas de adsorção construídas utilizando o programa OriginPro $2017^{\circledR}$, plotando-se a concentração de azul de metileno em equilíbrio $\left(\mathrm{C}_{\mathrm{eq}}\right)$, na abscissa e a quantidade do corante adsorvido $\left(\mathrm{q}_{\mathrm{e}}\right)$ na ordenada. A qualidade dos ajustes foi avaliada através do coeficiente de correlação linear $\mathrm{r}^{2} \mathrm{e}$ da função estatística raiz quadrada do erro médio quadrático normalizado (RMSE). As equações correspondentes ao modelo de Langmuir [35] (Equação 3) e Freundlich [36] (Equação 4) são expressas em ordem:

$$
\mathrm{q}_{\mathrm{e}}=\frac{\mathrm{q}_{\mathrm{max}} \cdot \mathrm{K}_{\mathrm{L}} \cdot \mathrm{C}_{\mathrm{eq}}}{1+\mathrm{K}_{\mathrm{L}} \cdot \mathrm{C}_{\mathrm{eq}}}
$$

Em que: $q$ refere-se à quantidade do soluto adsorvido por grama de adsorvente no equilíbrio $\left(\mathrm{mg} \mathrm{g}^{-1}\right)$. $\mathrm{q}_{\max }=\mathrm{e}$ a capacidade máxima de adsorção. $\mathrm{K}_{\mathrm{L}}$ (constante de Langmuir) é a constante de interação adsorvato/adsorvente $\left(\mathrm{L} \mathrm{mg}^{-1}\right)$. $\mathrm{C}_{\mathrm{eq}}=$ refere-se à concentração do adsorvato no equilíbrio.

$$
{ }^{\prime} \mathrm{qe}=\mathrm{K}_{\mathrm{F}} \mathrm{C}_{\mathrm{eq}}^{\mathrm{n}}
$$

Onde: $\mathrm{q}\left(\mathrm{mg} \mathrm{g}^{-1}\right)=$ é a quantidade de soluto adsorvido no equilíbrio. $\mathrm{C}_{\mathrm{eq}}\left(\mathrm{mg} \mathrm{L}^{-1}\right)=$ é a concentração de adsorvente em equilíbrio. $\mathrm{K}_{\mathrm{F}}\left(\mathrm{mg} \mathrm{g}^{-1}\right) /\left(\mathrm{mg}^{-\mathrm{L}^{-1}}\right)^{\mathrm{n}}=\mathrm{a}$ constante de Freundlich, e $\mathrm{n}=\mathrm{o}$ parâmetro de intensidade de Freundlich, que indica a magnitude da força motriz de adsorção ou a heterogeneidade da superfície. 


\section{RESULTADOS E DISCUSSÃO}

\subsection{Análise de rendimento do hydrochar}

A carbonização hidrotermal é reconhecida como uma reação lenta, na qual o tempo reacional pode variar de alguns minutos a alguns dias. O tempo influencia apenas as reações de hidrólise até um certo intervalo, além do qual não ocasiona nenhum impacto específico no processo. Por outro lado, a temperatura é sugerida como o parâmetro chave para o processo HTC, oferecendo calor de desintegração para fragmentação das ligações presentes na estrutura da biomassa [37]. O efeito da temperatura no rendimento do hydrochar é demonstrado na Figura 1. Conforme observa-se, o aumento da temperatura influenciou negativamente o rendimento, que variou entre $27,43 \%\left(190{ }^{\circ} \mathrm{C}\right)$ e $46,25 \%\left(170{ }^{\circ} \mathrm{C}\right)$. Essa diminuição do rendimento com o aumento da temperatura pode ser explicada pela formação de produtos líquidos e subprodutos gasosos, principalmente pela degradação da hemicelulose [38,39]. Resultados na literatura apontam que o aumento da temperatura tende a acelerar o processo de degradação e solubilização da biomassa pelas reações hidrotermais, resultando em um rendimento solido final baixo [29]. Nesse aspecto, à medida que a temperatura da reação hidrotermal aumenta, a água no estado subcrítico reforça a dissolução de compostos orgânicos da biomassa, resultando na queda de rendimento do hydrochar [31] devido ao aumento da decomposição da estrutura lignocelulósica durante a carbonização hidrotermal [40].

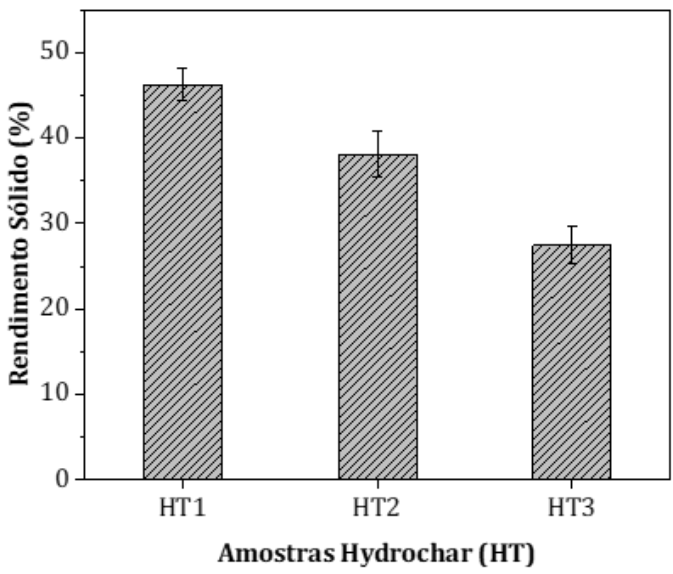

Figura 2: Análise de rendimento do hydrochar obtido em diferentes temperaturas: HT1 $\left(170{ }^{\circ} \mathrm{C}\right)$, HT2 $\left(180{ }^{\circ} \mathrm{C}\right)$, HT3 $\left(190{ }^{\circ} \mathrm{C}\right)$.

A observação de que o rendimento do hydrochar diminuiu com o aumento da temperatura de carbonização hidrotermal está bem estabelecida na literatura, como destacado por BENAVENTE et al. [41]. O rendimento observado nos testes realizados com a biomassa em estudo foi semelhante aos $48,10 \%$ verificado por YANG et al. [42] durante a carbonização hidrotérmica de cascas de nozes. Segundo esses autores, o teor de lignina na biomassa apresenta a maior contribuição para o rendimento do hydrochar. No entanto, considerando o fato do trabalho ter sido realizado com uma única biomassa, a principal perda no rendimento se deve à degradação da hemicelulose. Quando são comparadas biomassas diferentes, o rendimento é relacionado ao teor de lignina no material, pois quanto maior a quantidade de lignina, maior o rendimento.

\subsection{Análise elementar do hydrochar e da biomassa in natura}

A composição elementar das cascas do fruto in natura e dos hydrochars obtidos é demonstrada na Tabela 1. Os teores de carbono, hidrogênio, nitrogênio e oxigênio da casca in natura foram de 43,04\%, 5,46\%, 0,54\% e 50,96\%, respectivamente. Em uma análise geral, independente dos tratamentos utilizados, o teor de carbono nos hydrochars desenvolvidos foi maior que o da casca sem tratamento. Dentre os testes realizados, o hydrochar obtido a $170{ }^{\circ} \mathrm{C}(\mathrm{HT} 1)$ apresentou o melhor resultado $(64,10 \%)$, ou seja, 21,10 pontos percentuais a mais que a biomassa in natura. 
Tabela 1: Análise elementar e razões atômicas H/C e O/C para as cascas de tingui (MP) e para o hydrochar desenvolvido em diferentes temperaturas reacionais. MP: Casca in natura. HT1: Hydrochar obtido a $170^{\circ} \mathrm{C}$. HT2: Hydrochar obtido a $180^{\circ} \mathrm{C}$. HT3: Hydrochar obtido a $190{ }^{\circ} \mathrm{C}$.

\begin{tabular}{lllllll}
\hline AMOSTRA & \multicolumn{3}{l}{ COMPONENTE ELEMENTAR (\%) } & \multicolumn{2}{c}{ RAZÃO ATÔMICA } \\
\cline { 2 - 7 } & C & H & N & O* & O/C & H/C \\
\hline MP & 43,04 & 5,46 & 0,54 & 50,90 & 0,88 & 1,55 \\
HT1 & 64,10 & 4,60 & 0,70 & 30,40 & 0,35 & 0,87 \\
HT2 & 61,80 & 4,30 & 0,60 & 33,20 & 0,40 & 0,83 \\
HT3 & 52,10 & 5,00 & 0,40 & 42,30 & 0,60 & 1,16 \\
\hline
\end{tabular}

*Calculado por diferença.

Geralmente os materiais carbonáceos apresentam teores de C entre 40-60\% [43]. Nesse contexto, todos os hydrochars obtidos apresentaram valores de $\mathrm{C}$ dentro da faixa mencionada. Entre as amostras analisadas, HT3 (hydrochar obtido a $190{ }^{\circ} \mathrm{C}$ ) apresentou o menor teor de carbono, enquanto HT1 ((hydrochar obtido a $170{ }^{\circ} \mathrm{C}$ ) apresentou o maior aumento em relação à casca in natura. Esse comportamento se mostrou semelhante ao trabalho desenvolvido por NIZAMUDDIN et al. [39], no qual os autores debatem sobre a obtenção de hydrochar a partir de carbonização hidrotermal da casca de palma. LAGINHAS et al. [43] também discutem que os maiores teores de $\mathrm{C}$ estão relacionados com baixas temperaturas de carbonização hidrotermal, inferiores a $200{ }^{\circ} \mathrm{C}$, o que se dá devido a liberação da matéria volátil durante as reações hidrotermais [39].

Em relação aos demais elementos, verificou-se que o teor de O diminuiu de 50,96\% para 42,39\% com o aumento da temperatura de carbonização hidrotermal. Esse comportamento também foi observado por LAGINHAS et al. [43] durante a carbonização hidrotermal de quitosana para obtenção de carbono ativado. $\mathrm{O}$ aumento de $\mathrm{C}$ e diminuição de $\mathrm{O}$ observados é atribuído às reações de descarboxilação e de desidratação que ocorrem no interior do reator de carbonização hidrotermal e que são responsáveis pela formação da estrutura final do hydrochar, estando diretamente relacionadas com a temperatura de tratamento [39] e com a composição da biomassa. De maneira geral, a diminuição das proporções elementares como influência do aumento da temperatura aponta o papel dessa variável em promover a desidratação e aromatização, o que pode ser vantajoso no uso do hydrochar como precursor para obtenção de carbonos ativados [44].

\subsection{Diagrama de Van Krevelen e avaliação do poder calorífico}

O diagrama de Van Krevelen é geralmente utilizado para obter informações gerais sobre a qualidade e a natureza de um combustível sólido [45]. A Figura 3 exibe o diagrama de Van Krevelen para a casca in natura e para os hydrochar obtidos. As zonas características para a turfa, lignito, carvão e antracito também são mostradas para fins de comparação. A evolução das relações atômicas também permite a estimativa do grau de desoxigenação da biomassa por descarboxilação, por desidratação ou por desmetanização. Como mostrado na Figura 3, as razões atômicas $\mathrm{O} / \mathrm{C}$ e H/C do hydrochar se apresentaram na faixa de 0,35-0,60 e 0,87-1,16,

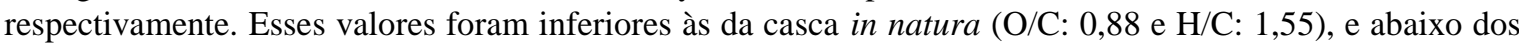
valores estimados para a turfa, cujas razões atômicas $\mathrm{O} / \mathrm{C}$ e $\mathrm{H} / \mathrm{C}$ estão estabelecidas em 0,64 e 1,36, respectivamente [7]. O diagrama de Van Krevelen mostra claramente que a evolução das razões atômicas H/C e $\mathrm{O} / \mathrm{C}$ da casca do fruto de tingui para as amostras hydrochar seguiram essencialmente os caminhos da desidratação e descarboxilação, enquanto a via de desmetanização foi insignificante. Esse comportamento foi semelhante à HTC de lamas de esgoto, celulose e outros tipos de biomassa lignocelulósica disponível na literatura [40,46,47]. Nesse processo, possivelmente, formaram-se ligações anidrido, éter e lactona [48]. Além disso, as tendências de desidratação e descarboxilação tornaram-se cada vez mais evidentes em temperaturas operacionais mais altas, semelhante ao trabalho desenvolvido por CAI et al. [40]. 


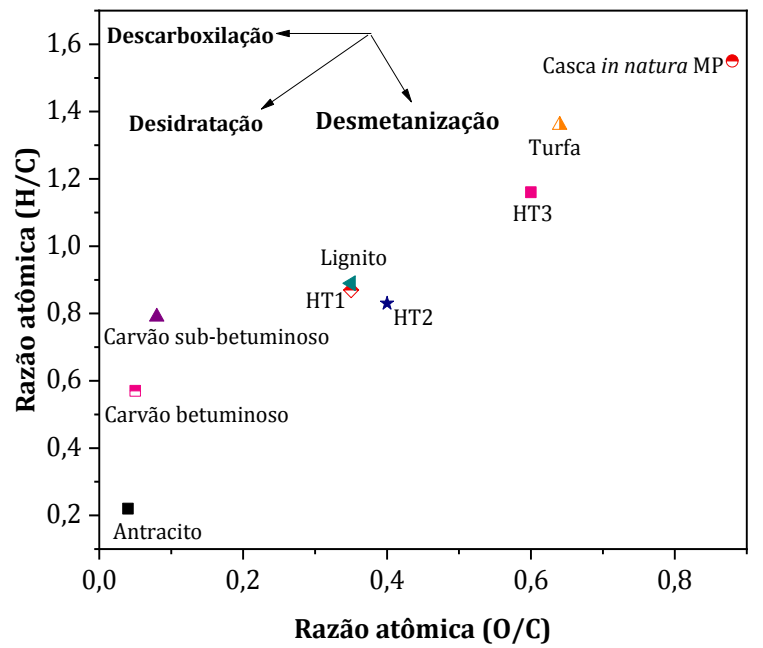

Figura 3: Diagrama de Van Krevelen para a casca in natura (MP) e os hydrochar (HT) desenvolvidos. Cinco tipos de carvões fósseis, isto é, antracito, betuminoso, sub-betuminoso, lignito e turfa são exibidos para comparação. MP: Casca in natura. HT1: Hydrochar obtido a $170^{\circ} \mathrm{C}$. HT2: Hydrochar obtido a $180^{\circ} \mathrm{C}$. HT3: Hydrochar obtido a $190^{\circ} \mathrm{C}$.

Em relação às modificações ocasionadas pelo efeito da temperatura de carbonização hidrotermal, verificou-se aumento das razões atômicas com o aumento da temperatura. Esse comportamento também foi evidenciado por YANG et al. [7], segundo o qual, a redução das relações atômicas H/C e O/C são ocasionadas pelos processos de descarboxilação, desidratação e desmetanização, os quais são intensificados com o aumento da temperatura. Nesse aspecto é possível chamar atenção para a amostras HT1 e HT2 (hydrochar obtido a 170 e $180{ }^{\circ} \mathrm{C}$, respectivamente), que apresentaram-se na região de lignito, ao passo que a amostra HT3 (hydrochar obtido a $190^{\circ} \mathrm{C}$ ) permaneceu na sobreposição da região de turfa, sugerindo alto teor carbonáceo do hydrochar desenvolvido em menores temperaturas. Comportamento semelhante foi verificado por HEILMANN et al. [49] durante a obtenção de hydrochar a partir de microalgas. Também se observou um leve declínio nas razões atômicas $\mathrm{H} / \mathrm{C}$ quando a temperatura aumentou de 170 para $180{ }^{\circ} \mathrm{C}$, sugerindo estágios diferentes nas reações de descarboxilação e desidratação. Contudo, como as razões foram próximas, tal efeito pode estar associado com a perda de carbono que é liberado como $\mathrm{CO}$ e $\mathrm{CO}_{2}$ de determinados componentes da biomassa, tais como o ácido urónico [50].

Dentre os diversos usos do hydrochar apontados na literatura, a correção do solo e o sequestro de carbono são duas aplicações amplamente discutidas. Contudo, SCHIMMELPFENNIG e GLASER [51] recomendam que materiais com tais finalidades tenham razão $\mathrm{H} / \mathrm{C}<0,6$ e relação $\mathrm{O} / \mathrm{C}<0,4$. Os hydrochars obtidos a partir da casca do fruto de tingui podem não ser ideais para tais finalidades, contudo, as amostras HT1 e HT2 podem ser usados como combustível sólido, uma vez que apresentaram relações H/C e O/C semelhantes às do lignito [52]. Essa suposição também pode ser verificada mediante estimativa do poder calorífico superior (PSC), calculado a partir dos dados de análise elementar [20]. Conforme se verifica na Tabela 3 , o poder calorífico superior aumentou em todas as condições reacionais em relação à casca in natura (MP), sendo o maior valor $\left(23,94 \mathrm{MJ} \mathrm{kg}^{-1}\right)$ atingido no tratamento hidrotérmico a $170{ }^{\circ} \mathrm{C}(\mathrm{HT} 1)$, possivelmente, devido ao seu maior teor de $\mathrm{C}$ e redução de $\mathrm{O}$ quando comparados aos demais materiais (Tabela 2).

Tabela 2: Poder calorífico superior (PCS) obtido a partir das cascas de tingui in natura e do hydrochar desenvolvido em diferentes condições reacionais.

\begin{tabular}{cc}
\hline AMOSTRA $^{*}$ & PODER CALORÍFICO $\left(\mathbf{M J . k g}^{-1}\right)$ \\
\hline MP & $14,81 \pm 0,51$ \\
HT1 & $23,94 \pm 0,79$ \\
HT2 & $22,14 \pm 0,71$ \\
HT3 & $18,33 \pm 0,50$ \\
\hline
\end{tabular}

*Onde. MP: Casca in natura. HT1: Hydrochar obtido a $170^{\circ} \mathrm{C}$. HT2: Hydrochar obtido a $180^{\circ} \mathrm{C}$. HT3: Hydrochar obtido a $190{ }^{\circ} \mathrm{C}$. 


\subsection{Caracterização química superficial por Espectroscopia no Infravermelho (FTIR)}

Os espectros FTIR das cascas in natura e do hydrochar são mostrados na Figura 4. As principais características são atribuídas à presença de lignina, hemicelulose e celulose. Analisando a Figura 3 nota-se a presença de picos a $3340 \mathrm{~cm}^{-1}$ em todos os materiais, os quais podem ser atribuídos a grupamentos hidroxila (estiramento $\mathrm{O}-\mathrm{H}$ em grupos hidroxilo e carbonilo), bem como à presença de água nas amostras [53]. Nessa mesma faixa também verificou-se a presença de picos em $2935 \mathrm{~cm}^{-1}$ em todas as amostras e em $2515 \mathrm{~cm}^{-1}$ no hydrochar obtido a $190{ }^{\circ} \mathrm{C}$ (HT3), os quais podem ser associados a vibrações de estiramento $\mathrm{C}-\mathrm{H}$ de grupos funcionais simples $\mathrm{CH}_{2}$ e $\mathrm{CH}_{3}$ e estiramento vibracional em estruturas aromáticas [50] respectivamente, sugerindo a presença de estruturas alifáticas e hidroaromáticas mesmo após tratamento hidrotermal [54]. Além desse fator, é possível que a presença desses picos esteja associada também às bandas de estiramento do grupo - $\mathrm{OH}$ da celulose causadas pelas vibrações de grupos hidroxilos ligados a hidrogênio [39].

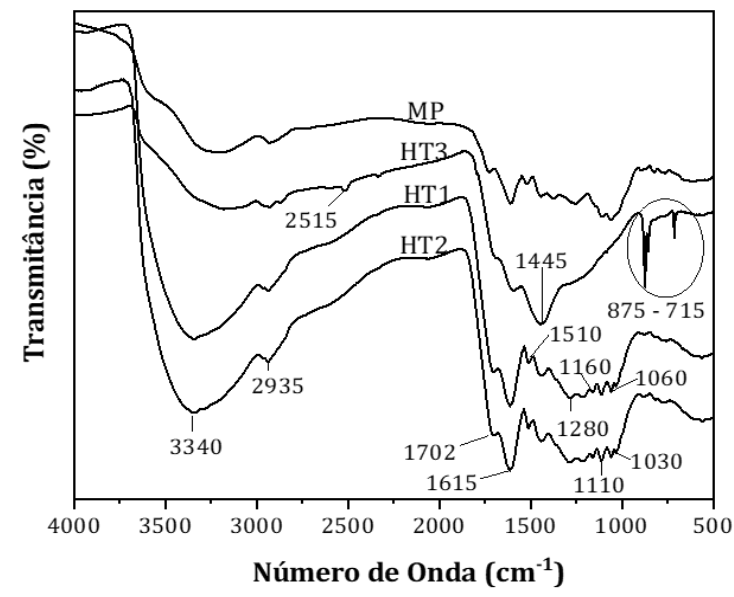

Figura 4: Espectros FT-IR da casca in natura (MP) e dos hydrochars desenvolvidos em diferentes condições reacionais. HT1: Hydrochar obtido a $170^{\circ} \mathrm{C}$. HT2: Hydrochar obtido a $180^{\circ} \mathrm{C}$. HT3: Hydrochar obtido a $190{ }^{\circ} \mathrm{C}$

Alguns picos mais intensos e outros adicionais foram observados entre $2000-1500 \mathrm{~cm}^{-1}$, região associada às vibrações de deformação axial de triplas ligações e duplas acumuladas. Um pico de fraca intensidade surgiu nas amostras em $1702 \mathrm{~cm}^{-1}$, o qual pode ser associado a estiramento de ligações $\mathrm{C}=\mathrm{O}$ de cetonas acíclicas, nas quais as vibrações ocorrem, principalmente, a partir de ésteres, ácidos carboxílicos ou aldeídos de celulose e lignina [31]. Por outro lado, houve diminuição no hydrochar obtido a $190{ }^{\circ} \mathrm{C}$ (HT3) do pico a $1615 \mathrm{~cm}^{-1}$ (estiramento vibracional $\mathrm{C}=\mathrm{C}$ dos anéis aromáticos presentes na lignina), sugerindo que os teores de lignina foram afetados mais intensamente nessa condição reacional. Além disso, em ambas as amostras observou-se a presença de um pico fraco em $1702 \mathrm{~cm}^{-1}$. A intensidade desse pico diminuiu significativamente quando a biomassa foi submetida ao tratamento hidrotermal em $190{ }^{\circ} \mathrm{C}$ (HT3) o que demonstra a ocorrência de reação de descarboxilação [31].

Os picos entre $1445 \mathrm{~cm}^{-1}$ e $1110 \mathrm{~cm}^{-1}$ foram característicos, podendo serem atribuídos ao estiramento $\mathrm{C}=\mathrm{C}$ em grupos aromáticos e em $\mathrm{C}-\mathrm{O}$ nos grupos $-\mathrm{OCH}_{3}$ da lignina [31]. Observou-se um aumento do primeiro pico à medida que se elevou a temperatura da reação hidrotermal, comportamento semelhante ao observado por NAKASON et al. [53] durante a produção de hydrochar a partir de raízes de mandioca. A presença desses picos sugere que a lignina não foi decomposta completamente durante a carbonização hidrotérmica, e alguns fragmentos residuais permaneceram no hydrochar [53], o que também foi amplamente discutido por GUO et al. [55] na obtenção de hydrochar a partir de eucalipto na faixa de temperatura de 220$300{ }^{\circ} \mathrm{C}$ entre $2-10 \mathrm{~h}$. Ainda nessa mesma faixa observou-se o desaparecimento de alguns picos entre 1055 (vibrações de estiramento $\mathrm{C}-\mathrm{O}$ da celulose e hemicelulose) e 1030 (vibrações de estiramento C-O da celulose e lignina) quando a biomassa foi tratada a $190{ }^{\circ} \mathrm{C}$, o que sugere que esses componentes lignocelulósicos foram parcialmente modificados e/ou degradados durante a condição hidrotérmica mencionada.

A diminuição em relação à casca in natura (MP) na intensidade das bandas entre $1000-1460 \mathrm{~cm}^{-1}$ nos hydrochars e bandas características entre 3000 e 3500 sugerem que os processos de desidratação e descarboxilação ocorreram durante o tratamento hidrotérmico, consistente com as análises das relações atômicas 
O/C- H /C, conforme abordado no diagrama de Van Krevelen [54]. Além dessas observações, a presença de grupos funcionais oxigenados sobre a superfície dos hydrochar pode permitir ao material desenvolvido funcionar também como adsorvente. Tais grupos são importantes em processos de adsorção em fase aquosa, águas residuais [56,57] e no desenvolvimento de carbono ativado, uma vez que tendem a permitir a interação entre os meios e facilitar a adsorção de espécies com polaridades específicas [58]. Essas possíveis aplicações podem tornar o material obtido um forte concorrente para aqueles desenvolvidos pelos métodos tradicionais de pirólise, os quais envolvem altas temperaturas reacionais.

Vários grupos com carbono oxidado, como ésteres ou lactonas também foram notados, representados pelos picos na região entre 1510 e $1110 \mathrm{~cm}^{-1}$ [2,31], conforme discutido anteriormente (Topico 3.4). Como mostrado na Figura 3, houve um pico adicional entre $875-715 \mathrm{~cm}^{-1}$ na amostra HT3 (hydrochar obtido a 190 ${ }^{\circ} \mathrm{C}$ ), que pode ser atribuído às vibrações de dobra $\mathrm{C}-\mathrm{H}$ aromáticas. Estas novas bandas sugerem a formação ou recombinação de anéis aromáticos com elevação da temperatura [59]. Observação semelhante a essa foi relatada por GAO et al. [31] durante a interpretação de espectros de infravermelho de hydrochars obtidos a partir de resíduos de eucalipto. A presença de tais picos característicos nas regiões analisadas são provavelmente devido à flexão para fora do plano de $\mathrm{C}-\mathrm{H}$ aromático em grupos $\mathrm{HC}=\mathrm{CH}$ [60], parcialmente indicando que as estruturas aromáticas foram favoravelmente formadas durante a carbonização hidrotérmica a $190{ }^{\circ} \mathrm{C}$ [50].

\subsection{Análise de Difratometria de Raios-X (XRD)}

Os difratogramas das amostras são apresentados na Figura 5, por meio dos quais observa-se na casca in natura um pico definido em valores de $2 \theta: 22^{\circ}-23^{\circ}$, o qual representam a fração de celulose cristalina [61,62]. Há ainda uma banda larga e discreta em $\approx 16^{\circ}$, que corresponde à fração amorfa de celulose, hemicelulose e lignina. Também notou-se diminuição da estrutura organizada dos materiais com o aumento da temperatura de 170 para $180^{\circ} \mathrm{C}$, o que deve-se às diversas reações simultâneas que ocorrem na condição hidrotermal e levam à degradação dos componentes lignocelulósicos presentes na casca do fruto.

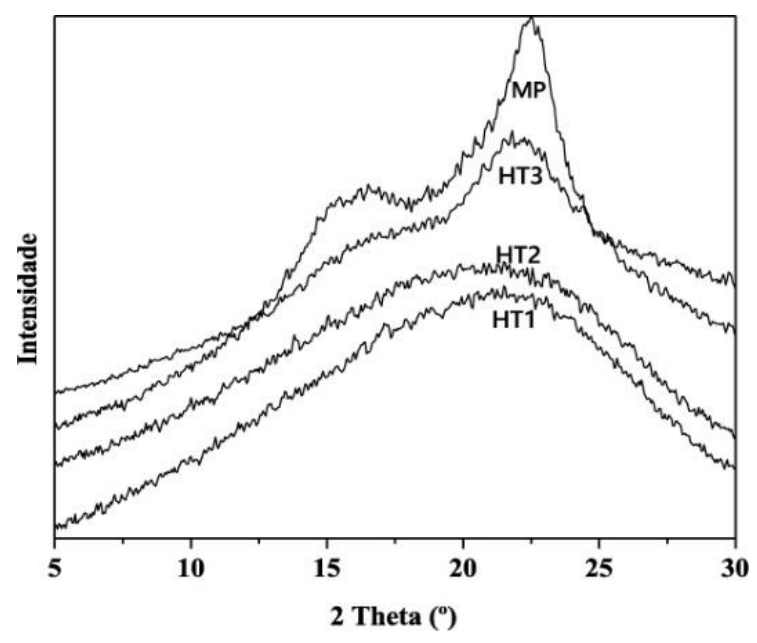

Figura 5: Difratograma da casca de tingui in natura (MP) e dos hydrochar obtido em diferentes condições reacionais. HT1: Hydrochar obtido a $170^{\circ} \mathrm{C}$. HT2: Hydrochar obtido a $180^{\circ} \mathrm{C}$. HT3: Hydrochar obtido a $190^{\circ} \mathrm{C}$

Durante o tratamento hidrotérmico da biomassa ocorre hidratação das fibras do material lignocelulósico e quebra das ligações de hidrogênio inter e intramolecular, e consequentemente, diminuição da estrutura semicristina, como é possível observar no difratograma apresentado pelas amostras HT1 (hydrochar tratado a $170{ }^{\circ} \mathrm{C}$ ) e $\mathrm{HT} 2$ (hydrochar tratado a $180{ }^{\circ} \mathrm{C}$ ) [50]. Com o aumento da temperatura e avanço das reações hidrotermais começam a ocorrer reações de condensação e recombinação de produtos secundários, alguns componentes são quebrados e outros perdidos, o que é observado durante a análise de rendimento. Além dessas características também é possível que ocorra reorganização da estrutura polimérica, voltando a ser cristalina ou uma estrutura mais organizada que difrata o raio-X na mesma região dos materiais cristalinos, o que se observou quando a biomassa foi tratada à temperatura hidrotérmica de $190{ }^{\circ} \mathrm{C}$ (HT3). 


\subsection{Análise das propriedades texturais superficiais do hydrochar}

Na Figura 6 tem-se as isotermas de adsorção-dessorção de $\mathrm{N}_{2}$ para as amostras de hydrochars (HT) obtidas. A parte inferior do loop é relacionada à adsorção e a parte superior representa a dessorção.

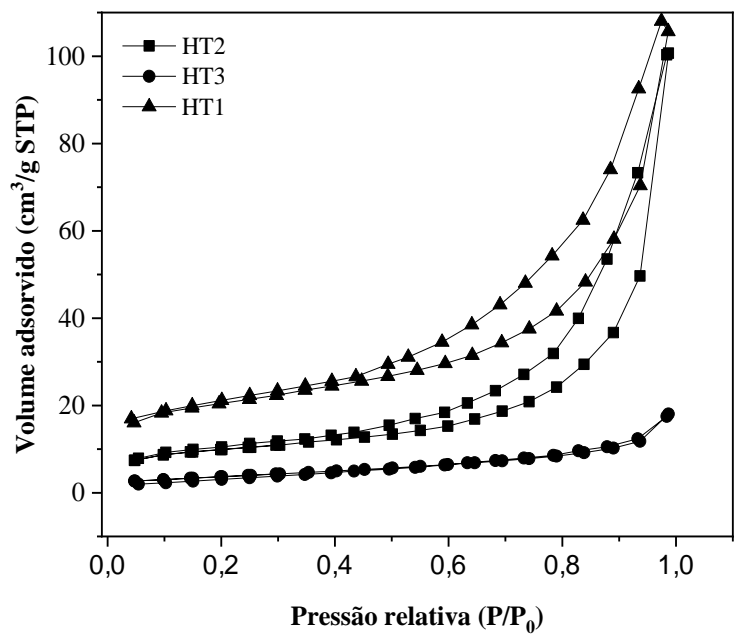

Figura 6: Isotermas de adsorção-dessorção de $\mathrm{N}_{2}$ para os hydrochars obtidos em diferentes condições reacionais. HT1: Hydrochar obtido a $170{ }^{\circ} \mathrm{C}$. HT2: Hydrochar obtido a $180^{\circ} \mathrm{C}$. HT3: Hydrochar obtido a $190^{\circ} \mathrm{C}$.

Segundo ZHANG et al. [63] a forma da isoterma fornecerá informações qualitativas a respeito do processo de adsorção e área superficial dos materiais. Além disso, o perfil isotérmico dará uma visão do tipo e da estrutura dos poros. Analisando a Figura 6, inicialmente nota-se que que as isotermas mostraram-se semelhante à isoterma do Tipo IV segundo definição da IUPAC e análogas às obtidas por RONIX et al. [64] durante o desenvolvimento de hydrochar a partir da casca de café. As características desse tipo de isoterma são o loop de histerese, que está associado à condensação capilar e indicativo da presença de mesoporos na estrutura dos hydrochars. Analisando os loops de histerese de acordo coma IUPAC, observa-se que os hydrochars com as maiores áreas superficiais apresentaram histerese do tipo H4, indicativo de mesoporos em forma de fenda, com uma distribuição de tamanho de poro largo [65].

$\mathrm{Na}$ Tabela 3 são expressos os valores das análises BET (área superficial) e BJH (volume e tamanho médio dos poros) do hydrochar (HT) e das cascas in natura (MP). Os resultados obtidos demonstram que o aumento da temperatura de 170 para $180{ }^{\circ} \mathrm{C}$ reduziu em aproximadamente $10 \mathrm{~m}^{2} \mathrm{~g}^{-1}$ a área superficial específica e cerca de $34 \mathrm{~m}^{2} \mathrm{~g}^{-1}$ à temperatura de $190^{\circ} \mathrm{C}$, demonstrando que o aumento da temperatura afeta negativamente a área superficial específica, comportamento também observado por MUMME et al. [66] durante a carbonização hidrotermal de milho e celulose. É possível que a modificação da área superficial seja devido à ruptura das ligações de hidrogênio na estrutura lignocelulósica, que é influenciada pela temperatura e tempo reacional, capazes de romper a estrutura fibrosa da biomassa, e consequentemente, produzir alguns poros na superfície do hydrochar [39].

Tabela 3: Propriedades texturais da biomassa in natura (MP) e do hydrochar (HT) obtido em diferentes condições reacionais.

\begin{tabular}{cccc}
\hline \multirow{2}{*}{ AMOSTRA $^{*}$} & \multicolumn{2}{c}{ MULTI-POINT BET } & \multicolumn{2}{c}{ MÉTODO BJH } \\
\cline { 2 - 4 } & ÁREA SUPERFICIAL $\left(\mathbf{m}^{\mathbf{2}} \mathbf{~}^{-1}\right)$ & VOLUME DE POROS $\mathbf{( \mathbf { c m } ^ { \mathbf { 3 } } \mathbf { g } ^ { - 1 } )}$ & TAMANHO DE POROS $(\mathbf{A})$ \\
\hline HT1 & 44,0 & 0,144 & 18,70 \\
HT2 & 34,0 & 0,151 & 18,50 \\
HT3 & 10,0 & 0,025 & 18,80 \\
MP & $>5$ & 0,003 & 1,54 \\
\hline
\end{tabular}


*Onde. MP: Biomassa in natura. HT1: Hydrochar obtido a $170^{\circ} \mathrm{C}$. HT2: Hydrochar obtido a $180^{\circ} \mathrm{C}$. HT3: Hydrochar obtido a $190{ }^{\circ} \mathrm{C}$

Embora os hydrochars desenvolvidos tenham apresentado área superficial específica baixa quando comparados aos carbonos ativados, que geralmente exibem área superficial específica superior a $200 \mathrm{~m}^{2} \mathrm{~g}^{-1}$, os resultados foram superiores a uma variedade de hydrochar obtidos na literatura. MINARET e DUTTA [67] por exemplo, trabalhando com casca de milho sobre condições hidrotérmicas obtiveram materiais com área superficial entre 7,0 e 5,0 $\mathrm{m}^{2} \mathrm{~g}^{-1}$, operando a $260{ }^{\circ} \mathrm{C}$ por $15 \mathrm{~min}$. MUMME et al.[66] em experiências conduzidas com carbonização hidrotérmica de milho e celulose demonstraram que o hydrochar com a área superficial mais alta e o maior volume de poros foi obtido a partir da celulose a $230{ }^{\circ} \mathrm{C}$ por $6 \mathrm{~h}$, o qual apresentou área BET de $28 \mathrm{~m}^{2} \mathrm{~g}^{-1}$ e $0,369 \mathrm{~cm}^{3} \mathrm{~g}^{-1}$, respectivamente. Em outro estudo, SEVILLA e FUERTES [68] relataram uma área superficial de $30 \mathrm{~m}^{2} \mathrm{~g}^{-1}$ para o hydrochar obtido a partir da carbonização hidrotérmica da celulose, e TITIRICI et al. [69] encontraram área superficial específica de 34,0 12,0 e $15,0 \mathrm{~m}^{2} \mathrm{~g}^{-1}$ para hydrochars obtidos a partir de pinhas, folhas de pinheiro e folhas de carvalho, respectivamente.

As baixas áreas superficiais BET apresentadas pelos hydrochars deve-se ao fato desses materiais apresentarem estrutura porosa pequena e pouco desenvolvida [59]. Nessas condições, os valores calculados para a área superficial específica correspondem somente à superfície externa [70], o que torna necessário melhorias na estrutura porosa e na área superficial para permitir a sua utilização em áreas como catálise e em processos de adsorção [66]. Tais melhorias podem ser obtidas a partir da combinação entre metodologias de ativação química e física, capazes de levar ao desenvolvimento de materiais com áreas superficiais superiores a $3000 \mathrm{~m}^{2} \mathrm{~g}^{-1}$, podendo chegar a $3420 \mathrm{~m}^{2} \mathrm{~g}^{-1}$ [71]. A síntese de carbonos ativados porosos a partir de hydrochar é vantajosa, uma vez que o hydrochar exibe propriedades especiais em termos de funcionalidades de superfície, particularmente grupos funcionais oxigenados, os quais tendem a influenciar os processos de ativação [72,73].

\subsection{Avaliação da capacidade de adsorção na remoção de azul de metileno (AM)}

\subsubsection{Eficiência de adsorção (\%)}

Um teste preliminar de adsorção foi realizado de maneira a determinar a eficiência de adsorção do azul de metileno e escolher os melhores hydrochars para aplicação dos modelos de isotermas. Para fins de comparação também foi utilizado carvão ativado comercial (CAC). A partir da Figura 7 observa-se que o hydrochar obtido a $180{ }^{\circ} \mathrm{C}$ (HT2) apresentou a melhor eficiência de adsorção, seguida pela amostra tratada a $170{ }^{\circ} \mathrm{C}$ (HT1). Esse valor mostrou-se próximo à percentagem de adsorção do carbono ativado comercial, demonstrando os hydrochar obtidos como uma alternativa aos carbonos ativados tradicionais. Embora a casca de tingui in natura tenha apresentado capacidade superior ao hydrochar HT3 (hydrochar obtido a $190{ }^{\circ} \mathrm{C}$ ), o uso de biomassas lignocelulósicas como material adsorvente encontra algumas limitações devido à sua natureza heterogênea e à capacidade de liberação em meio aquoso de extrativos e outros componentes estruturais. Se correlacionadas com a área superficial especifica, as altas capacidades de adsorção dos hydrochars podem ser resultado da presença de grupos funcionais oxigenados distribuídos na superfície do material [74], os quais facilitam o processo de adsorção por propriedades eletrostáticas. Considerando os resultados preliminares, as amostras HT1 (hydrochar obtido a $170^{\circ} \mathrm{C}$ ) e HT2 (hydrochar obtido a $180^{\circ} \mathrm{C}$ ) foram selecionadas para avaliação da capacidade máxima de adsorção e aplicação dos modelos de isotermas.

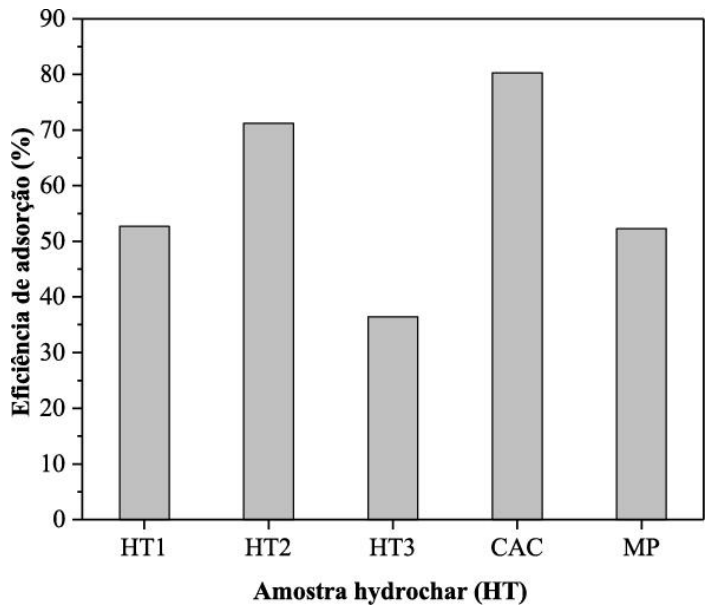


Figura 7: Eficiência de adsorção (\%) de azul de metileno pelos hydrochars (HT), pela casca in natura (MP) e pelo carbono ativado comercial (CAC). HT1: Hydrochar obtido a $170{ }^{\circ} \mathrm{C}$ ). HT2: Hydrochar obtido a $180^{\circ} \mathrm{C}$. HT3: Hydrochar obtido a $190{ }^{\circ} \mathrm{C}$. Solução teste: $250 \mathrm{mg} \mathrm{L}{ }^{-1}$. Dose de adsorvente: $10 \mathrm{mg}$. Temperatura $30{ }^{\circ} \mathrm{C}$. Período reacional: $24 \mathrm{~h}$. Velocidade de agitação: $150 \mathrm{rpm}$.

\subsubsection{Isotermas de adsorção e ajuste dos modelos de Langmuir e Freundlich aos dados experimentais}

A Figuras 8 ilustra as isotermas de adsorção ajustadas aos modelos de Freundlich e Langmuir, as quais relacionam a quantidade adsorvida de azul de metileno por massa de adsorvente $\left(\mathrm{q}_{\mathrm{eq}}\right)$ e as concentrações restantes $\left(\mathrm{C}_{\mathrm{eq}}\right)$ nas soluções aquosas.
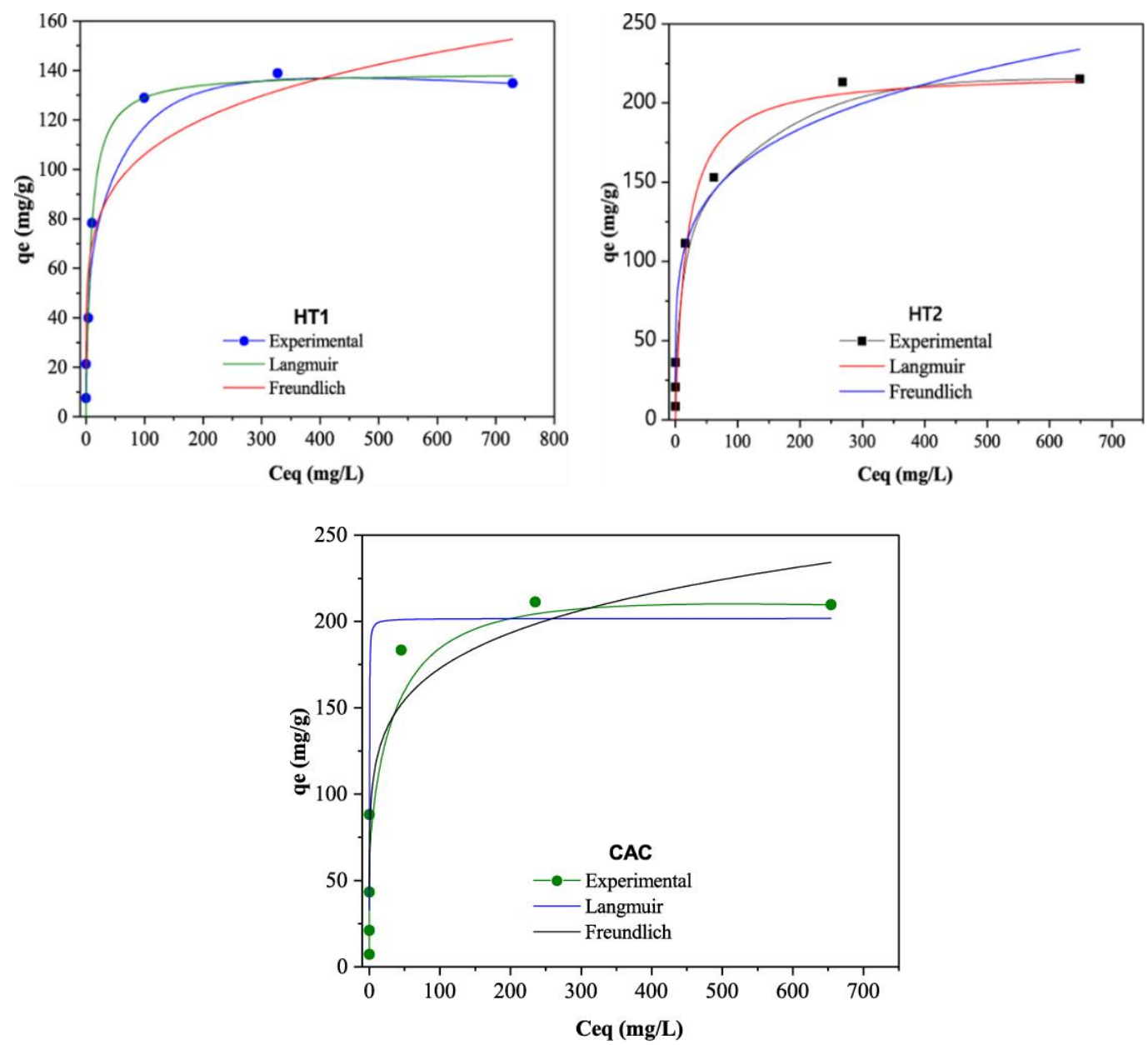

Figura 8: Isotermas de adsorção de AM ajustadas aos modelos de Langmuir e Freundlich. HT1: Hydrochar obtido a 170 ${ }^{\circ} \mathrm{C}$. HT2: Hydrochar obtido a $180^{\circ} \mathrm{C}$. CAC: Carbono ativado comercial. Massa do adsorvente: $10 \mathrm{mg}$. Soluções: 10-1000 mg. $\mathrm{L}^{-1}$. Volume: $10 \mathrm{~mL}$. Temperatura ambiente $\left(28 \pm 2{ }^{\circ} \mathrm{C}\right)$.

As isotermas de equilíbrio de adsorção podem ser classificadas em quatro tipos, segundo a sua inclinação inicial, denominadas: S, L, H e C. Cada isoterma permite inferir sobre o comportamento do fenômeno de adsorção, sendo úteis para compreender os mecanismos do processo e diagnosticar a natureza da adsorção [75,76]. Analisando o formato das isotermas na Figura 8 é possível classificá-las como tipo L, as quais caracterizam processos de adsorção em que há afinidade entre as partículas do adsorvente pelo adsorvato, apresentando certa concavidade. No entanto, ocorre diminuição na disponibilidade dos sítios de adsorção quando a concentração de azul de metileno aumenta, ou seja, a massa do adsorvato retida por unidade de massa do adsorvente é alta para uma baixa concentração de equilíbrio do adsorvato na fase líquida [7577]. Nesse aspecto, o carbono ativado comercial (CAC) atingiu o equilíbrio na maior concentração, seguido 
pelo hydrochar obtido a $180{ }^{\circ} \mathrm{C}(\mathrm{HT} 2)$ e $170{ }^{\circ} \mathrm{C}(\mathrm{HT} 1)$, respectivamente, que atingiram o equilíbrio em concentrações próximas às do carbono ativado comercial.

Os desempenhos de todos os materiais foram confirmados pela aplicação dos modelos de adsorção de Langmuir e Freundlich. Os valores dos parâmetros de cada uma das equações são apresentados na Tabela 4 e foram obtidos a partir de regressão não-linear, bem como o valor do coeficiente de determinação $\left(\mathrm{r}^{2}\right)$ e a função estatística raiz quadrada do erro médio quadrático normalizado (RMSE), permitindo verificar as diferenças entre as características e propriedades dos hydrochars na capacidade de adsorção.

Tabela 4: Parâmetros das equações de Langmuir e Freundlich para adsorção de azul de metileno nos hydrochars (HT) desenvolvidos e no carbono ativado comercial (CAC).

\begin{tabular}{|c|c|c|c|c|c|c|c|c|}
\hline \multirow{3}{*}{ AMOSTRAS } & \multicolumn{4}{|c|}{ ISOTERMA DE LANGMUIR } & \multicolumn{3}{|c|}{ ISOTERMA DE FREUNDLICH } & \multirow[b]{3}{*}{ RMSE } \\
\hline & \multicolumn{4}{|c|}{ PARÂMETROS } & \multicolumn{3}{|c|}{ PARÂMETROS } & \\
\hline & $\mathrm{Q}_{\operatorname{MAX}}\left(\mathrm{mg} \cdot \mathrm{g}^{-1}\right)$ & $\mathrm{KL}\left(\mathrm{L} \cdot \mathrm{mg}^{-1}\right)$ & $r^{2}$ & RMSE & $\mathbf{N}$ & $\mathrm{KF}\left(\mathrm{mg} \cdot \mathrm{g}^{-1}\right)$ & $r^{2}$ & \\
\hline HT1 & $139,38 \pm 6,65$ & $0,12 \pm 0,03$ & 0,96 & 1,05 & $5,45 \pm 1,09$ & $45,55 \pm 5,22$ & 0,90 & 3,00 \\
\hline HT2 & $202,40 \pm 7,06$ & $0,05 \pm 0,01$ & 0,96 & 2,50 & $4,87 \pm 0,46$ & $61,96 \pm 7,35$ & 0,91 & 4,40 \\
\hline CAC & $219,40 \pm 5,07$ & $0,16 \pm 0,04$ & 0,92 & 1,15 & $6,18 \pm 0,60$ & $82,05 \pm 8,65$ & 0,85 & 8,70 \\
\hline
\end{tabular}

Onde: $\mathrm{Q}_{\max }=$ Capacidade máxima de adsorção. $\mathrm{KL}=$ Constante de Langmuir. $\mathrm{N}=$ parâmetro de intensidade de Freundlich. $\mathrm{KF}=$ Constante de Freundlich.

A partir da Tabela 4, verifica-se que os coeficientes de correlação foram superiores para o ajuste das isotermas ao modelo de Langmuir, a qual também apresentou menores valores RMSE (raiz quadrada do erro médio quadrático normalizado), demonstrando que a isoterma de Langmuir foi a que melhor explicou o comportamento de adsorção do azul de metileno nas amostras avaliadas. Observou-se tambem que os hydrochars HT2 (obtido a $180{ }^{\circ} \mathrm{C}$ ) e HT1 (obtido a $170{ }^{\circ} \mathrm{C}$ ) apresentaram adsorção máxima de 202,40 e 139,38 $\mathrm{mg} \mathrm{g}^{-1}$, respectivamente, valores próximos ao verificado no carbono ativado comercial $\left(219,40 \mathrm{mg} \mathrm{g}^{-1}\right)$, que geralmente apresentam área superficial específica superior a $200 \mathrm{~m}^{2} \mathrm{~g}^{-1}$. Resultados semelhantes a esses foram observados por ZHANG et al. [78] durante a remoção de azul de metileno empregando atapalgite funcionalizada com ácido cloroacético através de processo hidrotermal a $180{ }^{\circ} \mathrm{C}$ durante $48 \mathrm{~h}$. Sob essas condições os autores conseguiram uma capacidade máxima de adsorção de $207.48 \mathrm{mg} \mathrm{g}^{-1}$ de azul de metileno, no entanto, as condições de tratamento foram marcadas por longo período reacional e funcionalização ácida, o que não foi empregado no trabalho atual, com a utilização apenas de água e um tempo menor de reação (5 h). Por outro lado, os valores de adsorção máximos demonstrados por HT1 (hydrochar obtido a $170{ }^{\circ} \mathrm{C}$ ) e HT2 (hydrochar obtido a $180{ }^{\circ} \mathrm{C}$ ) foram superiores aos verificados por RONIX et al. [64] no hydrochar desenvolvido a partir das cascas de café, o qual demonstrou capacidade de adsorção em monocamada de 34,85 $\mathrm{mg} \mathrm{g}^{-1}$ para azul de metileno. Vale ressaltar, no entanto, que grande parte dos resultados disponíveis na literatura para adsorção de azul de metileno em meio aquoso foram obtidos a partir de adsorção em carbonos ativados (CA). Convencionalmente, CA são obtidos por meio da pirólise de materiais orgânicos, seguido de ativação química ou física em altas temperaturas, superiores a $500{ }^{\circ} \mathrm{C}$ e em multietapas, o que ainda configura um processo dispendioso.

\section{CONCLUSÕES}

A carbonização hidrotermal das cascas do fruto de tingui (Magonia pubescens A. St. Hil. - Sapindaceae) mostrou-se eficaz no desenvolvimento de um material com diferentes propriedades físico-químicas e alta capacidade de adsorção para a molécula do corante azul de metileno. Analisando as condições do processo hidrotermal, verificou-se que em temperaturas superiores a $180^{\circ} \mathrm{C}$, menores rendimentos de hydrochar são obtidos. A análise elementar mostrou um teor de carbono superior a $61 \%$, tendo todas as amostras apresentado elevação em comparação com a casca in natura. Os resultados também exibiram diminuição do teor de oxigênio, evidenciando que o comportamento de combustão das cascas de tingui foi melhorado após carbonização hidrotermal. Essa observação foi comprovada através da análise do poder calorífico superior (PSC), que chegou a 23,94 $\mathrm{MJ} \mathrm{kg}^{-1}$. A partir da análise de difração de Raios-X, verificou-se modificação da estrutura cristalina da celulose dos hydrochars em comparação com a casca in natura. Os hydrochars obtidos em menor temperatura $\left(170\right.$ e $\left.180^{\circ} \mathrm{C}\right)$ apresentaram as maiores áreas superficiais e as maiores capacidades de adsorção do corante azul de metileno $\left(139,38-202,40 \mathrm{mg} \mathrm{g}^{-1}\right.$, respectivamente), e na temperatura de $180{ }^{\circ} \mathrm{C}$ 
a capacidade de adsorção ficou próxima a do carbono ativado comercial $\left(219,40 \mathrm{mg} \mathrm{g}^{-1}\right)$. Tais valores são inéditos para hydrochar desenvolvidos em uma única etapa e sem modificação química ou física. Dessa forma, a carbonização hidrotérmica se mostrou como uma alternativa à pirólise clássica para converter as cascas do fruto de tingui em um produto útil, com elevado teor carbonáceo, área superficial específica acima dos valores disponíveis na literatura e capacidade de adsorção de azul de metileno superior a vários hydrochars obtidos a partir de diferentes tipos de biomassas estudadas para o mesmo propósito. Assim, os materiais desenvolvidos podem ser aproveitados como novos adsorventes e uma alternativa aos tradicionais carbonos ativados para remoção de azul de metileno.

\section{AGRADECIMENTOS}

À Universidade de Brasília (UNB), ao Laboratório de Materiais e Combustíveis (LMC) e ao Instituto Federal de Goiás-Campus Goiânia (IFG), pelo apoio técnico e laboratorial. À Coordenação de Aperfeiçoamento de Pessoal de Nível Superior (CAPES) pela concessão das bolsas de doutorado e de mestrado e à Fundação de Amparo à Pesquisa no DF (FAP-DF) pelo financiamento da pesquisa.

\section{BIBLIOGRAFIA}

[1] TITIRICI, M. M., ANTONIETTI, M., "Chemistry and materials options of sustainable carbon materials made by hydrothermal carbonization", Chemical Society Reviews, v. 39, n. 1, pp. 103-16, Jan. 2010.

[2] ROMÁN, S. et al., "Production of low-cost adsorbents with tunable surface chemistry by conjunction of hydrothermal carbonization and activation processes", Microporous and Mesoporous Materials, v. 165, pp. 127-133, Jan. 2013.

[3] CATAlKopRU, A. K., KANTARLI, I. C., YANIK, J., "Effects of spent liquor recirculation in hydrothermal carbonization”, Bioresource Technology, v. 226, pp. 89-93, Fev. 2017.

[4] LIBRA, J. A et al., "Hydrothermal carbonization of biomass residuals: a comparative review of the chemistry, processes and applications of wet and dry pyrolysis", Biofuels, v. 2, n. 1, pp. 71-106, Jan. 2011.

[5] POERSCHMANN, J. et al., "Hydrothermal carbonization of poly(vinyl chloride)", Chemosphere, v. 119, pp. 682-689, Ago. 2015.

[6] HU, B. et al., "Engineering Carbon Materials from the Hydrothermal Carbonization Process of Biomass", Advanced Materials, v. 22, n. 7, pp. 813-828, Fev. 2010.

[7] YANG, W. et al., "Fuel properties and combustion kinetics of hydrochar prepared by hydrothermal carbonization of bamboo", Bioresource Technology, v. 205, pp. 199-204, Abr. 2016.

[8] BAI, C.-X., SHEN, F., QI, X.-H., "Preparation of porous carbon directly from hydrothermal carbonization of fructose and phloroglucinol for adsorption of tetracycline", Chinese Chemical Letters, v. 28, pp. 960-962, Mai. 2017.

[9] ANTERO, R. V. P., OLIVEIRA, S. B., BARBOSA, D. P., "Aplicação da metodologia de carbonização hidrotermal (HTC) no desenvolvimento de carvão ativado polimérico a partir de resíduos poliméricos", Revista de Química Industrial, v. 83, n. 747, pp. 100-112, Abr. 2015.

[10] KHATAEE, A. et al., "Ultrasound-assisted removal of Acid Red 17 using nanosized Fe3O4-loaded coffee waste hydrochar", Ultrasonics Sonochemistry, v. 35, pp. 72-80, Mar. 2017.

[11] BELDA, R. M., LIDÓN, A., FORNES, F., "Biochars and hydrochars as substrate constituents for soilless growth of myrtle and mastic", Industrial Crops and Products, v. 94, pp. 132-142, Dez. 2016.

[12] DAI, Y. et al., "Utilizations of agricultural waste as adsorbent for the removal of contaminants: A review", Chemosphere, v. 211, pp. 235-253, Nov. 2018.

[13] TRAN, H. N. et al., "Insight into the adsorption mechanism of cationic dye onto biosorbents derived from agricultural wastes", Chemical Engineering Communications, v. 204, n. 9, pp. 1020-1036, Jul. 2017.

[14] SILVA, A. B. C. et al., "Análise da utilização de cerâmica vermelha como adsorvente na remoção do corante têxtil Direct Blue de uma solução aquosa", Matéria (Rio de Janeiro), v. 22, n. 3, Ago. 2017.

[15] PATHANIA, D., SHARMA, S., SINGH, P., "Removal of methylene blue by adsorption onto activated carbon developed from Ficus carica bast", Arabian Journal of Chemistry, v. 10, pp. S1445-S1451, Fev. 
2017.

[16] ISLAM, M. A. et al., "Methylene blue adsorption on factory-rejected tea activated carbon prepared by conjunction of hydrothermal carbonization and sodium hydroxide activation processes", Journal of the Taiwan Institute of Chemical Engineers, v. 52, pp. 57-64, Jul. 2015.

[17] AFROZE, S., et al., "Adsorption of methylene blue dye from aqueous solution by novel biomass Eucalyptus sheathiana bark: equilibrium, kinetics, thermodynamics and mechanism", Desalination and Water Treatment, v. 57, n. 13, pp. 5858-5878, Jan. 2015.

[18] ALTINTIG, E., et al., "Effective removal of methylene blue from aqueous solutions using magnetic loaded activated carbon as novel adsorbent", Chemical Engineering Research and Design, v. 122, pp. 151163, Jun. 2017.

[19] OLIVEIRA, F. M., et al., "Avaliação de processo adsortivo utilizando mesocarpo de coco verde para remoção do corante azul de metileno", Matéria (Rio de Janeiro), v. 23, n. 4, n. 4, Dez. 2018.

[20] BORGES, W. M. DA S., et al., "Produção, caracterização e avaliação da capacidade adsortiva de carvões ativado em forma de briquete", Matéria (Rio de Janeiro), v. 21, n. 4, pp. 930-942, Dez. 2016.

[21] RATTER, J. A., RIBEIRO, J. F., S., B., "The Brazilian Cerrado vegetation and threats to its biodiversity", Annals of Botany, v. 80, n. 3, pp. 223-230, Set. 1997.

[22] LORENZI, H., Árvores brasileiras: manual de identificação e cultivo de plantas arbóreas nativas do Brasil, 2. ed., v. 3., Brasil, Instituto Plantarum de Estudos da Flora, 2002.

[23] DE CÁSSIA, S., et al., Estabelecimento de Magonia pubescens A.St.Hil. (Sapindaceae) submetidas a diferentes tipos de solos, https://www.researchgate.net/publication/237635378. Acessado em Julho de 2018.

[24] FAGG, C. W., et al., "Useful Brazilian plants listed in the manuscripts and publications of the Scottish medic and naturalist George Gardner (1812-1849)", Journal of Ethnopharmacology, v. 161, pp. 18-29, Fev. 2015.

[25] BRANDÃO, M., BUENDIA, J. P. L., MACEDO, J. F., Arvores nativas e exóticas do Estado de Minas Gerais, 1. ed., Minas Gerais, Empresa de Pesquisa Agropecuária de Minas Gerais, 2002.

[26] CAI, J., et al., "Review of physicochemical properties and analytical characterization of lignocellulosic biomass", Renewable and Sustainable Energy Reviews, v. 76, pp. 309-322, Set. 2017.

[27] MORAIS, R. L., et al., "Removal of synthetic sex hormones by hydrothermal carbonization", Anais da Academia Brasileira de Ciências, v. 90, n. 2, pp. 1327-1336, Mai. 2018.

[28] HEIDARI, M. et al., "A review of the current knowledge and challenges of hydrothermal carbonization for biomass conversion", Journal of the Energy Institute, Article in press.

[29] KAMBO, H. S., DUTTA, A., "A comparative review of biochar and hydrochar in terms of production, physico-chemical properties and applications", Renewable and Sustainable Energy Reviews, v. 45, pp. 359378, Mai. 2015.

[30] FANG, J., et al., "Hydrochars derived from plant biomass under various conditions: Characterization and potential applications and impacts", Chemical Engineering Journal, v. 267, pp. 253-259, Mai. 2015.

[31] GAO, P., et al., "Preparation and characterization of hydrochar from waste eucalyptus bark by hydrothermal carbonization", Energy, v. 97, pp. 238-245, Fev. 2016.

[32] YAO, Z., et al., "TGA-FTIR analysis of co-pyrolysis characteristics of hydrochar and paper sludge", Journal of Analytical and Applied Pyrolysis, v. 123, pp. 40-48, Jan. 2016.

[33] CHANNIWALA, S. A., PARIKH, P. P., "A unified correlation for estimating HHV of solid, liquid and gaseous fuels", Fuel, v. 81, n. 8, pp. 1051-1063, Mai. 2002.

[34] BARRETT, E. P., JOYNER, L. G., HALENDA, P. P., "The Determination of Pore Volume and Area Distributions in Porous Substances. I. Computations from Nitrogen Isotherms", Journal of the American Chemical Society, v. 73, n. 1, pp. 373-380, Jan. 1951.

[35] LANGMUIR, I., "The constitution and fundamental properties of solids and liquids. Part I: Solids", Journal of the American Chemical Society, v. 38, n. 11, pp. 2221-2295, Nov. 1916. 
[36] FREUNDLICH, H., “Über die Adsorption in Lösungen”, Zeitschrift für Physikalische Chemie, v. 57, n. 1, pp. 385-470, Out. 1907.

[37] NIZAMUDDIN, S., et al., "An overview of effect of process parameters on hydrothermal carbonization of biomass", Renewable and Sustainable Energy Reviews, v. 73, pp. 1289-1299, Jun. 2017.

[38] GHANIM, B. M., et al., "Hydrothermal carbonisation of poultry litter: Effects of treatment temperature and residence time on yields and chemical properties of hydrochars", Bioresource Technology, v. 216, pp. 373-380, Set. 2016.

[39] NIZAMUDDIN, S., et al., "Chemical, dielectric and structural characterization of optimized hydrochar produced from hydrothermal carbonization of palm shell”, Fuel, v. 163, pp. 88-97, Jan. 2016.

[40] CAI, J., et al., "Hydrothermal carbonization of tobacco stalk for fuel application", Bioresource Technology, v. 220, pp. 305-311, Nov. 2016.

[41] BENAVENTE, V., CALABUIG, E., FULlANA, A., "Upgrading of moist agro-industrial wastes by hydrothermal carbonization", Journal of Analytical and Applied Pyrolysis, v. 113, pp. 89-98, Mai. 2015.

[42] YANG, W., et al., "Elevating the fuel properties of Humulus lupulus, Plumeria alba and Calophyllum inophyllum L. through wet torrefaction”, Fuel, v. 146, pp. 88-94, Abr. 2015.

[43] LAGINHAS, C., NABAIS, J. M. V., TITIRICI, M. M., “Activated carbons with high nitrogen content by a combination of hydrothermal carbonization with activation", Microporous and Mesoporous Materials, v. 226, pp. 125-132, Mai. 2016.

[44] JAIN, A., BALASUBRAMANIAN, R., SRINIVASAN, M. P., “Tuning hydrochar properties for enhanced mesopore development in activated carbon by hydrothermal carbonization", Microporous and Mesoporous Materials, v. 203, pp. 178-185, Fev. 2015.

[45] KREVELEN, V., W., D., "Graphical-statistical method for the study of structure and reaction processes of coal”, Fuel, v. 29, pp. 269-284, 1950.

[46] HE, C., GIANNIS, A., WANG, J.-Y., "Conversion of sewage sludge to clean solid fuel using hydrothermal carbonization: Hydrochar fuel characteristics and combustion behavior", Applied Energy, v. 111, pp. 257-266, Nov. 2013.

[47] DÜDDER, H., et al., "Synthesis and characterization of lignite-like fuels obtained by hydrothermal carbonization of cellulose", Fuel, v. 171, pp. 54-58, Mai. 2016.

[48] MARTfuERTES, A. B., SEVILlA, M., FUERTES, A. B., "Chemical and structural properties of carbonaceous products obtained by hydrothermal carbonization of saccharides", Chemistry - A European Journal, v. 15, n. 16, pp. 4195-4203, 2009.

[49] HEILMANN, S. M., et al., "Hydrothermal carbonization of microalgae", Biomass and Bioenergy, v. 34, n. 6, pp. 875-882, Jun. 2010.

[50] SABIO, E., et al., "Conversion of tomato-peel waste into solid fuel by hydrothermal carbonization: Influence of the processing variables", Waste Management, v. 47, pp. 122-132, Jan. 2016.

[51] SCHIMMELPFENNIG, S., GLASER, B., "One Step Forward toward Characterization: Some Important Material Properties to Distinguish Biochars”, Journal of Environmental Quality, v. 41, n. 4, pp. 1001-1013, Ago. 2012.

[52] ZHANG, Y., et al., "Effects of temperature, time and acidity of hydrothermal carbonization on the hydrochar properties and nitrogen recovery from corn stover", Biomass and Bioenergy, v. 122, pp. 175-182, Mar. 2019.

[53] NAKASON, K., et al., "Characteristics of hydrochar and liquid fraction from hydrothermal carbonization of cassava rhizome”, Journal of the Energy Institute, v. 91, n. 2, pp 184-193, Abr. 2017.

[54] PARSHETTI, G. K., KENT HOEKMAN, S., BALASUBRAMANIAN, R., "Chemical, structural and combustion characteristics of carbonaceous products obtained by hydrothermal carbonization of palm empty fruit bunches", Bioresource Technology, v. 135, pp. 683-689, Mai. 2013.

[55] GUO, S., et al., "Characteristic evolution of hydrochar from hydrothermal carbonization of corn stalk", 
Journal of Analytical and Applied Pyrolysis, v. 116, pp. 1-9, Nov. 2015.

[56] DIPPOLD, M., BIRYUKOV, M., KUZYAKOV, Y., "Sorption affects amino acid pathways in soil: Implications from position-specific labeling of alanine", Soil Biology and Biochemistry, v. 72, pp. 180-192, Mai. 2014.

[57] PARSHETTI, G. K., et al., "Hydrothermal carbonization of sewage sludge for energy production with coal”, Fuel, v. 111, pp. 201-210, Set. 2013.

[58] MURSITO, A. T., HIRAJIMA, T., SASAKI, K., "Upgrading and dewatering of raw tropical peat by hydrothermal treatment", Fuel, v. 89, n. 3, pp. 635-641, Mar. 2010.

[59] REGMI, P., et al., "Removal of copper and cadmium from aqueous solution using switchgrass biochar produced via hydrothermal carbonization process", Journal of Environmental Management, v. 109, pp. 6169, Out. 2012.

[60] KUMAR, S., et al., "An Assessment of U(VI) removal from groundwater using biochar produced from hydrothermal carbonization", Journal of Environmental Management, v. 92, n. 10, pp. 2504-2512, Out. 2011.

[61] GAI, C., et al., "Hydrogen-rich gas production by steam gasification of hydrochar derived from sewage sludge", International Journal of Hydrogen Energy, v. 41, n. 5, pp. 3363-3372, Fev. 2016.

[62] DONAR, Y. O., ÇAĞLAR, E., SINAĞ, A., "Preparation and characterization of agricultural waste biomass based hydrochars", Fuel, v. 183, pp. 366-372, Nov. 2016.

[63] CHEN, W., et al., "Co-pyrolysis of lignocellulosic biomass and microalgae: Products characteristics and interaction effect”, Bioresource Technology, v. 245, pp. 860-868, Dez. 2017.

[64] RONIX, A., et al., "Hydrothermal carbonization of coffee husk: Optimization of experimental parameters and adsorption of methylene blue dye", Journal of Environmental Chemical Engineering, v. 5, n. 5, pp. 4841-4849, Out. 2017.

[65] ZHANG, S., et al., "Determining fractal dimensions of coal pores by FHH model: Problems and effects", Journal of Natural Gas Science and Engineering, v. 21, pp. 929-939, Nov. 2014.

[66] MUMME, J., et al., "Hydrothermal carbonization of anaerobically digested maize silage", Bioresource Technology, v. 102, n. 19, pp. 9255-9260, Out. 2011.

[67] MINARET, J., DUTTA, A., "Comparison of liquid and vapor hydrothermal carbonization of corn husk for the use as a solid fuel”, Bioresource Technology, v. 200, pp. 804-811, Jan. 2016.

[68] SEVILLA, M., FUERTES, A. B., "The production of carbon materials by hydrothermal carbonization of cellulose", Carbon, v. 47, n. 9, pp. 2281-2289, Ago. 2009.

[69] TITIRICI, M. M., et al., "A direct synthesis of mesoporous carbons with bicontinuous pore morphology from crude plant material by hydrothermal carbonization", Chemistry of Materials, v. 19, n. 17, pp. 42054212, Ago. 2007.

[70] FUERTES, A. B., et al., "Chemical and structural properties of carbonaceous products obtained by pyrolysis and hydrothermal carbonisation of corn stover", Soil Research, v. 48, n. 6-7, pp. 618-626, Jan. 2010 .

[71] FUERTES, A. B., SEVILlA, M., "Superior Capacitive Performance of Hydrochar-Based Porous Carbons in Aqueous Electrolytes", ChemSusChem, v. 8, n. 6, pp. 1049-1057, Mar. 2015.

[72] JAIN, A., BALASUBRAMANIAN, R., SRINIVASAN, M. P., "Hydrothermal conversion of biomass waste to activated carbon with high porosity: A review", Chemical Engineering Journal, v. 283, pp. 789805, Jan. 2016.

[73] SEVIlla, M., FERrero, G. A., FUERTES, A. B., "Beyond KOH activation for the synthesis of superactivated carbons from hydrochar", Carbon, v. 114, pp. 50-58, Abr. 2017.

[74] WANG, N., et al., "Influence of Bisphenol A on thyroid volume and structure independent of iodine in school children”, PLOS ONE, v. 10, n. 10, pp. 1-12, Out. 2015.

[75] GILES, C. H., SMITH, D., HUITSON, A., “A general treatment and classification of the solute 
adsorption isotherm. I. Theoretical", Journal of Colloid and Interface Science, v. 47, n. 3, pp. 755-765, Jun. 1974.

[76] SPOSITO, G., The Chemistry of Soils, 3 ed., USA, Oxford University Press, 2008.

[77] NASCIMENTO, R. F., et al., Adsorção: Aspectos teóricos e aplicações ambientais, 1 ed., Fortaleza, Imprensa Universitária, 2014.

[78] ZHANG, Z., WANG, W., WANG, A., "Highly effective removal of methylene blue using functionalized attapulgite via hydrothermal process", Journal of Environmental Sciences, v. 33, pp. 106-115, Jul. 2015.

\section{ORCID}

Romario Victor Pacheco

0000-0002-3680-345X

Meire Ellen Gorete Ribeiro Domingos

0000-0002-1699-8720

Lorrayne Lins Suzuki

0000-0002-0125-8949

Sergio Botelho de Oliveira

0000-0003-0961-938X

Satu Ojala

0000-0001-9520-9293

Andressa Regina Vasques Mendonça

0000-0001-7546-6815

Sarah Silva Brum

0000-0002-0728-3627 